\title{
Recursos didáticos digitais para o ensino de Química durante a pandemia da Covid-
}

\section{9}

\author{
Digital teaching resources for teaching Chemistry during the Covid-19 pandemic \\ Recursos didácticos digitales para la enseñanza de la Química durante la pandemia del Covid-19
}

Recebido: 16/03/2021 | Revisado: 25/03/2021 | Aceito: 30/03/2021 | Publicado: 08/04/2021

Natália Costa Rodrigues

ORCID: https://orcid.org/0000-0002-1578-1669 Instituto Federal de Educação, Ciência e Tecnologia de Mato Grosso, Brasil

E-mail: nataliaarv@hotmail.com

Natállia Roberta Souza

ORCID: https://orcid.org/0000-0002-4349-8203 Instituto Federal de Educação, Ciência e Tecnologia de Mato Grosso, Brasil E-mail: natalliarobertabio@gmail.com

Samira Gabrielle Oliveira Patias

ORCID: https://orcid.org/0000-0003-0848-8875 Instituto Federal de Educação, Ciência e Tecnologia de Mato Grosso, Brasil E-mail: samirapatias1@gmail.com

Edione Teixeira de Carvalho

ORCID: https://orcid.org/0000-0002-1208-3961 Instituto Federal de Educação, Ciência e Tecnologia de Mato Grosso, Brasil

E-mail: edione.carvalho@svc.ifmt.edu.br

Leandro Carbo

ORCID: https://orcid.org/0000-0001-5514-7040 Instituto Federal de Educação, Ciência e Tecnologia de Mato Grosso, Brasil E-mail: Leandro.carbo@svc.ifmt.edu.br

Ane Francielly da Silva Santos

ORCID: https://orcid.org/0000-0003-2730-9991 Instituto Federal de Educação, Ciência e Tecnologia de Mato Grosso, Brasil E-mail: ane.santos@ifmt.svc.edu.br

\begin{abstract}
Resumo
A Química é uma ciência que apresenta linguagem própria, microscópica e geralmente abstrata, o que dificulta a aprendizagem de grande parte dos alunos. Durante o ensino remoto, devido à pandemia causada pelo novo coronavírus, o processo de ensino e aprendizado se torna ainda mais desafiador. Dessa forma, os professores precisaram se reinventar e adotar novas metodologias para atender as demandas dessa nova modalidade de ensino. $\mathrm{O}$ uso de modelos didáticos no ensino tem sido relatado na literatura como uma estratégia eficaz para a aprendizagem. Sendo assim, o objetivo deste trabalho consiste em avaliar o desempenho de materiais didáticos audiovisuais (vídeos), como intervenção para o ensino de configuração eletrônica dos elementos. A metodologia foi do tipo qualitativa, utilizando como instrumento de validação da eficiência dos modelos didáticos um questionário aplicado a 134 alunos do $1^{\circ}$ ano do ensino médio do Instituto Federal de Mato Grosso, campus São Vicente. Os percentuais das respostas indicaram que o método de ensino utilizado é uma estratégia eficaz para a compreensão do conteúdo de configuração eletrônica.
\end{abstract}

Palavras-chave: Ensino remoto; Modelos didáticos; Ensino de química; Configuração eletrônica.

\begin{abstract}
Chemistry is a science that has its own language, microscopic and generally abstract, which makes it difficult for most students to learn. During remote education, due to the pandemic caused by the new coronavirus, the teaching and learning process becomes even more challenging. Thus, teachers needed to reinvent themselves and adopt new methodologies to meet the demands of this new teaching modality. The use of didactic models in teaching has been reported in the literature as an effective strategy for learning. Therefore, the objective of this work is to evaluate the performance of audiovisual teaching materials (videos), as an intervention for teaching the electronic configuration of the elements. The methodology was qualitative, using a questionnaire applied to 1341 st year high school students at the Federal Institute of Mato Grosso, São Vicente campus, as a validation tool for the efficiency of didactic models. The percentages of responses indicated that the teaching method used is an effective strategy for understanding the content of electronic configuration.
\end{abstract}

Keywords: Remote teaching; Didactic models; Chemistry teaching; Electronic configuration. 


\begin{abstract}
Resumen
La química es una ciencia que tiene un lenguaje propio, microscópico y generalmente abstracto, lo que dificulta el aprendizaje de la mayoría de los estudiantes. Durante la educación remota, debido a la pandemia causada por el nuevo coronavirus, el proceso de enseñanza y aprendizaje se vuelve aún más desafiante. Así, los docentes necesitaban reinventarse y adoptar nuevas metodologías para atender las demandas de esta nueva modalidad de enseñanza. El uso de modelos didácticos en la enseñanza ha sido reportado en la literatura como una estrategia efectiva para el aprendizaje. Por tanto, el objetivo de este trabajo es evaluar el desempeño de los materiales didácticos audiovisuales (videos), como una intervención para la enseñanza de la configuración electrónica de los elementos. La metodología fue cualitativa, utilizando un cuestionario aplicado a 134 estudiantes de primer año de secundaria del Instituto Federal de Mato Grosso, campus São Vicente, como herramienta de validación de la eficiencia de modelos didácticos. Los porcentajes de respuestas indicaron que el método de enseñanza utilizado es una estrategia eficaz para comprender el contenido de la configuración electrónica.
\end{abstract}

Palabras clave: Enseñanza remota, Modelos didácticos; Enseñanza de la química; Configuración electrónica.

\title{
1. Introdução
}

Os avanços tecnológicos e descobertas científicas não livrou o mundo da pandemia de Covid-19 desde o início de 2020. A chegada abrupta do vírus acarretou impactos globais em âmbitos sociais, políticos, culturais, econômicos, tecnológicos e na saúde. Na educação, a pandemia afetou diretamente o processo de escolarização. O distanciamento social tem sido a principal medida para o combate ao vírus, no entanto, essa alternativa provoca impactos no âmbito educacional, e para dar continuidade às aulas, o ensino remoto foi à possibilidade mais viável. Nesse contexto, instituições de ensino e professores tiveram que se reinventar e adotar novas práticas para atender as demandas do ensino remoto (Oliveira, Neto \& Oliveira, 2020).

Esta realidade é completamente diferente da qual os professores estavam habituados, nem mesmo os professores que já adotavam Ambientes Virtuais de Aprendizagem (AVA) imaginavam uma mudança de realidade tão rápida, emergencial e praticamente obrigatória. A "saída da zona de conforto" gera aprendizado, e esse processo de transição é valioso para educação, uma vez que, os professores aprenderam a utilizar plataformas de videoconferência como: Zoom Meetings, Skype, Google Hangouts e Google Meet; e plataformas de aprendizagem como: Google Clasroom, Moodle e Microsoft Teams (Corrêa \& Brandemberg, 2021).

A migração de professores e estudantes para plataformas de ensino remoto trouxe novos desafios, a pandemia causada pelo novo corona vírus exigiu a adoção de metodologias alternativas que, até então, não era seguida por grande parte dos professores. Aliado ao ensino remoto, surgiu a necessidade de novas metodologias e práticas pedagógicas, buscando alternativas inovadoras que auxiliem o aluno no processo de ensino e aprendizado e que desenvolva a autonomia nos estudos. Um dos impactos negativos da pandemia da Covid-19 na educação foi o aumento da evasão escolar, que demandou dos professores ações estratégicas de curto prazo (Senhoras, 2020). Dessa forma, o professor tornou-se criador de conteúdos digitais e utilizador de diferentes recursos tecnológicos.

As Orientações Educacionais Complementares aos Parâmetros Curriculares Nacionais, (PCN+) do Ensino Médio, já ressaltava a importância da diversificação dos materiais e recursos didáticos, tais como a utilização de vídeos, filmes, músicas entre outros, para o ensino de Ciências da Natureza (Química, Física e Biologia) e Matemática e suas tecnologias. Os usos de diversos recursos dão maior abrangência ao conhecimento, possibilitam a integração de diferentes saberes, motivam, instigam e favorecem o debate sobre assuntos do mundo contemporâneo (Brasil \& MEC, 2002). A Base Curricular Nacional (BNCC) apresenta o uso de tecnologia como uma das competências gerais da educação, em que é possível construir uma aprendizagem crítica e significativa (Brasil, 2018).

De acordo com Moreira et. al. (2020), com o crescimento do fenômeno dos vídeos na web, tornou-se bastante acessível capturar, editar e partilhar pequenos vídeos, utilizando equipamentos pouco dispendiosos e softwares gratuitos e 
livres. O uso dessas ferramentas em ambientes virtuais de aprendizagem se tornou uma opção válida e eficaz como metodologia de ensino.

Para os estudantes, a era da informática também trouxe benefícios, a computação na escola coloca os estudantes frente a um novo processo educativo, onde podem prosseguir, frear, voltar, reestudar ou aprimorar conceitos vistos em sala de aula, além de aprofundar e criar suas investigações e interpretações sobre o assunto, baseados em outras informações pesquisadas ou discutidas com diferentes autores ou colegas, via internet (Heckler, Saraiva \& Filho, 2007).

Nesse contexto, e considerando a necessidade do ensino remoto, é fundamental o aperfeiçoamento do professor para o uso de tecnologias. O desenvolvimento de animações como modelo de ensino é extremamente interessante, pois as animações podem combinar imagens, sons, textos, simulações e vídeos de uma forma simultânea. Todos esses recursos auxiliam o aluno no processo de ensino e aprendizado de forma mais eficiente em comparação aos meios tradicionais de ensino (Gonçalves, Veit \& Silveira, 2006).

Em aulas presenciais, o método de ensino tradicional, pautado em livros didáticos, memorização, pouca contextualização, com uma didática maçante e cansativa, colabora para a formação de um aluno treinado a repetir conceitos sem associá-los ao seu cotidiano. No entanto, existem alguns conteúdos abstratos na área das Ciências que são de difícil assimilação e contextualização. Nestes casos, o uso de representações didáticas com materiais lúdicos é significativo, pois estimulam o interesse do aluno pela disciplina de Química e tornam a aula mais atraente e agradável (Neto \& Moradillo, 2016). Dessa forma, uma sugestão satisfatória para abordagem de temas complexos que, além de não causar interesse na maioria dos alunos, dificilmente são compreendidos apenas com as teorias de livros didáticos, são as atividades dinâmicas.

A Química é uma Ciência de linguagem própria, suas estruturas e conceitos são bem específicos, detalhados e geralmente abstratos, exigindo do aluno dedicação, empenho e atenção durante as aulas, dessa forma, o processo de aprendizagem em Química se torna ainda mais desafiador quando a disciplina é ministrada a distância (Sales, 2020). O conteúdo de configuração eletrônica está entre os assuntos de maior dificuldade no ensino de Química no nível médio, por se tratar de um tema distante do cotidiano e que possui um elevado nível de abstração (Bianco \& Meloni, 2019). Sendo assim, os discentes ao terem contato com a Química no $1^{\circ}$ ano do Ensino Médio, apresentam dificuldades de compreender certos conceitos e, em consequência disso, poderão apresentar também dificuldades em assuntos posteriores que dependem deste tópico, como: organização da tabela periódica em grupos e períodos, ligação iônica e covalente, reações químicas e outros.

A tecnologia presente nos dias atuais, já dominada por grande parte dos jovens estudantes, é bastante apropriada para realização do ensino remoto (Valente et al., 2020). A busca por estratégias para o ensino remoto, a utilização de uma metodologia didática inovadora se faz necessária, especialmente quando atividades em grupo e aulas experimentais não podem ser desenvolvidas, e pensando nas dificuldades apresentadas pelos discentes quanto à compreensão do diagrama de Linus Pauling e as regras descritas nos livros didáticos para o conteúdo de distribuição de elétrons, a aplicação de modelos didáticos como suporte à educação, além de estimular o interesse do aluno, muda o paradigma da educação tradicional e se faz extremamente fundamental.

Desse modo, no presente trabalho pretendeu-se investigar a eficiência do material didático audiovisual como suplemento complementar aos livros didáticos, para o ensino do conteúdo de configuração eletrônica nas turmas de $1^{\circ}$ ano do Ensino Médio. Os objetivos específicos desse estudo consistiram no desenvolvimento de animações e/ou vídeos como estratégia, para ser acessado em Ambientes Virtuais de Aprendizagem (AVA) enquanto durar o ensino remoto; análise do rendimento dos estudantes antes e após a aplicação do modelo didático audiovisual por meio de questionários; avaliação da receptividade dos estudantes ao material desenvolvido (aspecto qualitativo) e para servir como uma sugestão de modelo didático que futuramente poderá ser utilizado nas aulas presenciais. 


\section{Metodologia}

O presente estudo foi realizado com alunos do $1^{\circ}$ ano do curso Técnico em Agropecuária Integrado ao Ensino Médio do Instituto Federal de Mato Grosso (IFMT) campus São Vicente, totalizando 134 discentes distribuídos em seis turmas. Devido à pandemia o estudo foi desenvolvido com o auxílio das plataformas digitais, Google Classroom e Google Meet.

A fim de nortear a pesquisa, inicialmente foi levantada a seguinte hipótese: $\mathrm{O}$ uso de animações/vídeos como modelo didático audiovisual no ensino do conteúdo de configuração eletrônica para os discentes do $1^{\circ}$ ano do Ensino Médio pode facilitar o processo de ensino aprendizagem em relação aos métodos convencionais de ensino?

No início da pesquisa, realizou-se um encontro virtual com os discentes, por meio da plataforma de videoconferência Google Meet. Esse encontro teve como objetivo esclarecer aos alunos como o trabalho seria executado, as etapas a serem seguidas e também pleitear a colaboração dos discentes para a realização do projeto.

No segundo momento, foram produzidos os materiais didáticos audiovisuais, sendo eles: uma vídeo-aula interativa com animações (Modelo Didático Interativo) e uma vídeo-aula composta por um modelo didático-pedagógico confeccionado com materiais alternativos (Modelo Didático Pedagógico), sendo ambos utilizados para explicação do diagrama de Linus Pauling. Os materiais audiovisuais retém o interesse do espectador, pois é possível que o professor articule fontes, textos, vídeos vozes e saberes (Rezende \& Struchiner, 2009).

Durante todo o trabalho, o levantamento de dados foi obtido por meio da aplicação de questionários aos estudantes. Conforme afirma (Gil, 2002), "o questionário é uma investigação composta de perguntas, a fim de se obter conhecimentos prévios, opiniões, sentimentos e visões sobre situações do cotidiano por parte dos investigados". Dessa forma, foi enviado um questionário prévio aos discentes, contendo questões objetivas e dissertativas, de forma a analisar a opinião dos estudantes sobre: maiores dificuldades da disciplina de química, motivação para aulas não presenciais, metodologias de ensino e utilização de modelos didáticos para aulas mais interativas. Os questionários foram aplicados antes e após a apresentação do material digital aos discentes.

\subsection{Modelo Didático Interativo}

Pensando na necessidade de uma metodologia diferenciada para o ensino de Química durante as aulas remotas, foi desenvolvida uma vídeo-aula interativa sobre configuração eletrônica, com o uso de diversos aplicativos, mais especificamente: Microsoft Powerpoint 2016, OpenShot e OBS studio, que são programas fáceis de serem adquiridos e executados e oferecem diversos recursos que podem ser explorados por seus usuários.

As animações foram desenvolvidas pelo programa Microsoft PowerPoint, que é um software bastante comum de apresentação de slides e está incluso no pacote Microsoft Office. No entanto, o PowerPoint pode ir muito além, as novas atualizações do programa apresentaram diferentes recursos, tornando a ferramenta mais profissional (Sanches, 2016). Este programa apresenta facilidade de acesso, tendo em vista que está instalado na maioria dos computadores, é utilizado para apresentações e oferece diversos recursos para criação de materiais alternativos, podendo incluir: imagens, sons, textos, gifs e vídeos. O software conta também com diversos efeitos de animações personalizadas e avançadas. No plano de fundo do slide foi colocada a imagem de um quadro verde, para maior aproximação do ambiente escolar. Os elétrons foram representados por bolinhas vermelhas no formato 3D (Figura 1). À medida que era realizada a explicação da configuração eletrônica de um átomo, os elétrons eram inseridos, um de cada vez em seus orbitais pelo efeito de animação chamado "elástico". 
Figura 1. Modelo Didático Interativo.

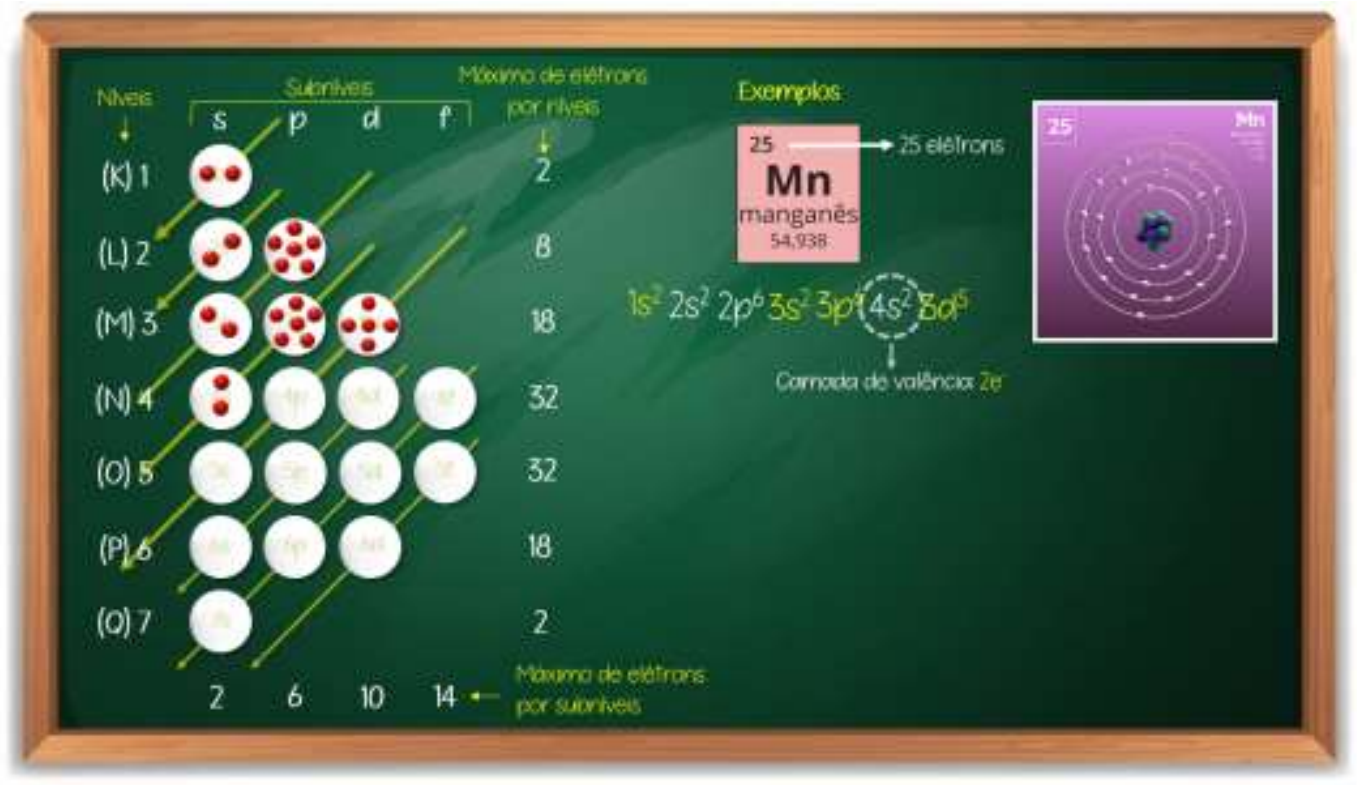

Fonte: Autores.

A gravação de tela e filmagem foram executadas pelo programa gratuito Open Broadcaster Software ou OBS studio. Os softwares apresentam recursos, como: captura de áudio, captura de vídeo, captura de tela e janela, imagens, textos entre outros. Para efeito mais didático utilizou-se o efeito "Chroma Key”, disponível no programa, a aula foi gravada em um fundo sólido verde e o cenário foi substituído pela simulação do quadro verde, dando a impressão de que a professora estava dentro de uma sala de aula.

Para edições como recortes e junção de vídeos foi utilizado o editor de vídeos OpenShot, que é um programa gratuito, fácil de utilizar e rápido para aprender, contém as funcionalidades mais populares, atendendo a principais necessidades para a edição de uma vídeo-aula.

\subsection{Modelo Didático Pedagógico}

Como sugestão para o ensino de configuração eletrônica em aulas presenciais e remotas, foi elaborado um modelo didático pedagógico, utilizando materiais de baixo custo e reaproveitando materiais que seriam descartados. Assim, torna-se interessante de utilizar formas alternativas de ensino, adaptando materiais alternativos encontrados no cotidiano como forma de ensino (Silva et al., 2017). Para a simulação dos orbitais, foi usado suporte de fita adesiva, que foram lixados e pintados com tinta branca para um melhor efeito visual. O suporte foi fixado em um quadro branco, e as informações do diagrama, tais como: setas, nomes de níveis e subníveis foram escritos com canetão. Para a representação dos elétrons foram manuseados "bolinhas de gude" de diferentes cores (Figura 2).

Posteriormente, foi gravada a vídeo aula utilizando o modelo e apresentando alguns exemplos de configuração eletrônica. 
Figura 2. Modelo Didático Pedagógico.

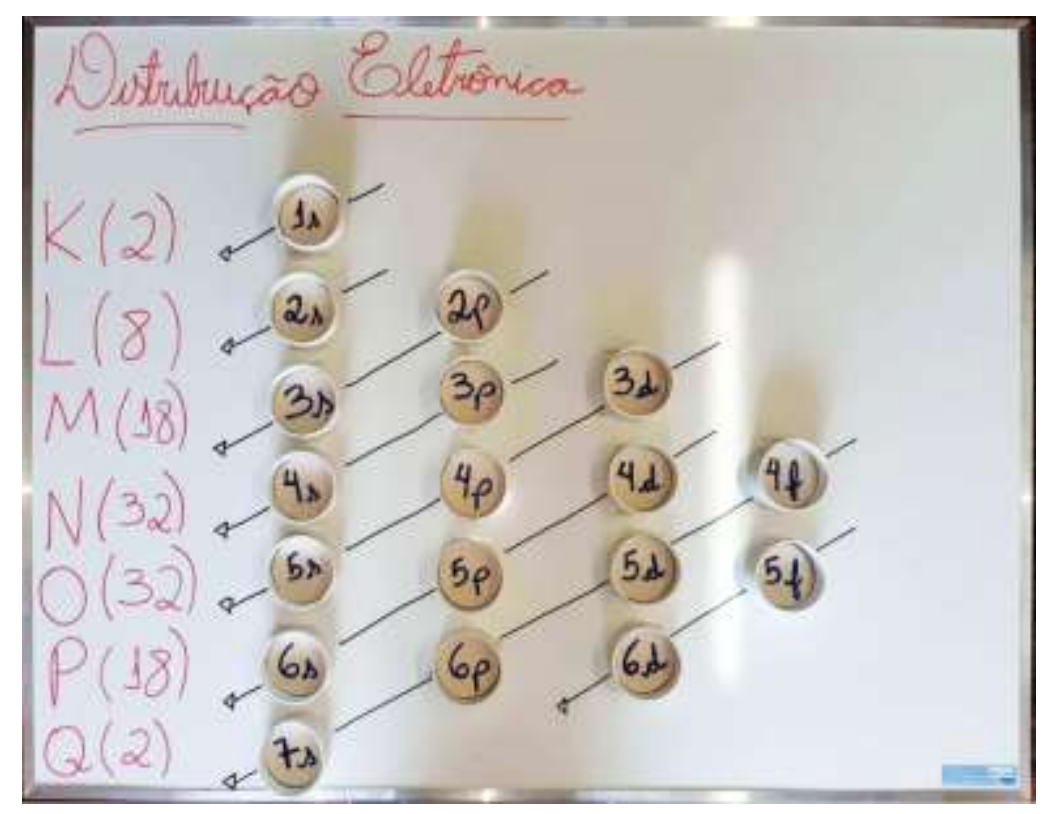

Fonte: Autores.

Os vídeos produzidos foram passados aos discentes como auxilio ao conteúdo que estava sendo vislumbrado em sala. Após assistirem aos vídeos, os alunos responderam a um novo questionário, desta vez com questões relacionadas diretamente a metodologia de ensino que foi executada com o objetivo de analisar as percepções dos estudantes sobre o modelo proposto e verificar se houve aumento na compreensão de configuração eletrônica.

\section{Resultados e Discussão}

O questionário prévio aplicado aos discentes anteriormente ao início da apresentação dos modelos didáticos consistiu em perguntas com o objetivo de analisar as percepções dos discentes acerca do ensino remoto, ensino de Química e o uso de modelos didáticos.

$\mathrm{Na}$ análise da primeira pergunta do questionário, enunciada: "Você acha que o modelo de ensino por meio de aulas presenciais é eficiente para aprendizagem?" observa-se que cerca de $50 \%$ dos discentes consideram o ensino presencial eficiente para a aprendizagem, $37 \%$ assinalaram a alternativa talvez e $10 \%$ não acham aulas presenciais eficientes, conforme os dados apresentados no Gráfico 1. 
Gráfico 1. Você acha que o modelo de ensino por meio de aulas presenciais é eficiente para aprendizagem?

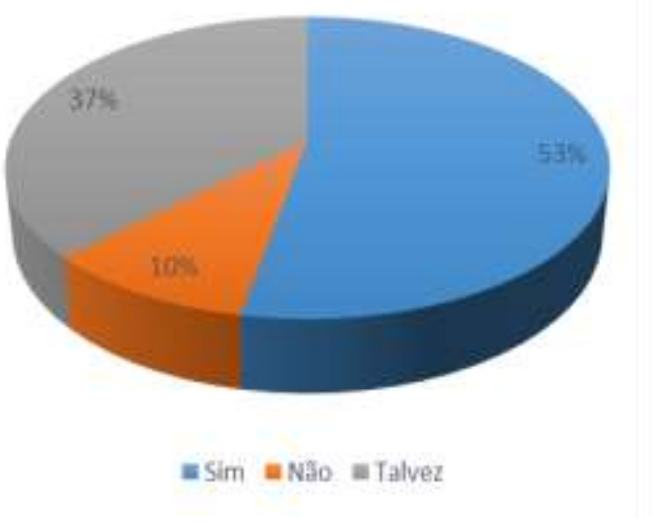

Fonte: Autores.

A segunda questão teve como finalidade analisar os motivos que fazem os alunos aprovarem ou não o ensino presencial. A Tabela 1 apresenta em categorias as principais razões pelas quais os discentes responderam "Sim" para eficiência do ensino presencial.

Tabela 1. Motivos da eficácia do ensino presencial.

\begin{tabular}{c|c}
\hline Categorias & Respostas dos discentes (\%) \\
\hline Melhor interação com os professores & 25 \\
Aulas práticas & 23 \\
Absorve melhor o conteúdo & 21 \\
Prestam mais atenção/mais motivação & 9 \\
Outros & 22 \\
\hline
\end{tabular}

Fonte: Autores.

É possível perceber que a maioria das justificativas de defesa do ensino presencial é a melhor interação dos estudantes com o professor, como revela as respostas: "É eficiente, pois os professores estão ali para tirar as dúvidas imediatamente e citam exemplos que muitas vezes ajudam na compreensão" e "Porque estamos em contato com o professor(a) e, até mesmo com os colegas, o que ajuda bastante, as vezes eles entendem melhor e nos ajudam a entender o que não conseguimos."

$\mathrm{Na}$ sequência, a possiblidade de aulas práticas presenciais é o fator que mais desperta interesse nos estudantes (23\%), como apresentado nas respostas: "Porque como o próprio lema do Campus diz (aprenda a fazer fazendo), sim as aulas teóricas são essenciais para se aprender, mas as práticas também fazem a diferença, porque ao fazer na prática as lembranças que ficam em nossas mentes serão mais dificil de esquecer, além de ter uma noção melhor de como fazer." e "Porque sempre é bom pôr a mão na massa e aprender fazendo". De acordo com Rezende \& Gomes (2018), as aplicações de modelos didáticos corroboram para a aderência entre a teoria e prática, promovendo a contextualização dos conteúdos. De fato, as aulas à distância limitam o conhecimento empírico como relatado pelo aluno "pôr a mão na massa", no entanto, a internet e os recursos tecnológicos podem auxiliar o professor com a demonstração de fenômenos aos seus alunos e trazer contribuição para o conhecimento, que pode ser uma solução para as aulas não presenciais.

Os alunos também relatam que absorvem melhor o conteúdo (21\%) e prestam mais atenção na aula (9\%) durante as aulas presenciais, como relata as seguintes respostas, respectivamente: "Eu acho eficiente porque quando explicam eu entendo 
de forma muito fácil" e "Por que em sala de aula os alunos tem uma concentração maior, a forma que os professores explicam é bem melhor."

Basicamente, são dois os principais motivos que cometem os estudantes a considerarem o ensino presencial ineficaz: falta de aulas práticas (64\%) e aulas monótonas (36\%), como mostra a tabela 2. Esses motivos foram relatados nas respostas dos discentes, "Acho que deveria ter um equilibrio entre as aulas teóricas e práticas" e "Aula vira um tédio, tem que ser de uma forma que o aluno se interessa". Estes resultados estão em consonância com os estudos realizados por Silva, Filha e Freitas (2016), no qual foi apresentada uma proposta didática baseada no uso de modelos didáticos para a representação da anatomia celular. $\mathrm{O}$ estudo demonstra que, em contrapartida às atividades tradicionais de ensino, as metodologias lúdicas e práticas colaboram para o interesse e participação dos alunos.

Tabela 2. Motivos da ineficácia do ensino presencial.

\begin{tabular}{c|c}
\hline Categorias & Respostas dos alunos (\%) \\
\hline Falta de aulas práticas & 64 \\
Aulas monótonas & 36 \\
\hline
\end{tabular}

Fonte: Autores.

Como observado no resultado da primeira questão, uma parte considerável dos alunos consideram a aula presencial eficaz para o ensino, no entanto, é necessário que o processo de ensino-aprendizado vá para além da sala de aula. A escola é o local onde maior parte do conhecimento técnico-científico é adquirida, no entanto, com o avanço da tecnologia, existem maneiras extraescolares que podem auxiliar o aluno na busca pelo conhecimento. Dessa forma, para verificar se os estudantes buscam outros meios complementares de ensino, foi feita a terceira pergunta: "Você consegue absorver os conteúdos somente através da explicação teórica ou busca outras maneiras de estudar, como vídeo aulas em plataformas digitais?” Os percentuais das respostas estão organizados no Gráfico 2.

Gráfico 2. Você consegue absorver os conteúdos somente através da explicação teórica ou busca outras maneiras de estudar, como vídeo aulas em plataformas digitais?

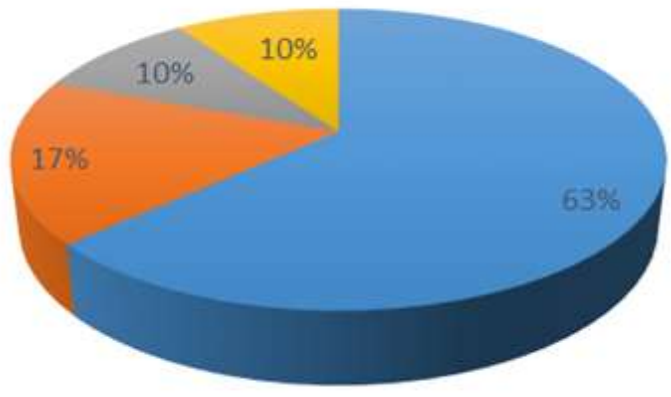

Busca outras maneiras de estudar wão busca outras maneiras de estudar

\section{․ㅡㄹ Consegue absorver apenas com a aula presencial}

$\equiv$ As vezes

Fonte: Autores.

Nota-se que mais de $50 \%$ dos estudantes responderam que buscam outras formas de absorver o conteúdo. Considerando o avanço das tecnologias, é possível que os alunos consigam, com facilidade, efetuar pesquisas de prováveis dúvidas em plataformas de sites educacionais de acesso gratuito. Outros 17\% dos alunos dizem conseguir absorver o conteúdo 
apenas com a aula presencial, 10\% buscam outras maneiras de estudar, apenas às vezes. Os 63\% 17\% 10\% 10\% Busca outras maneiras de estudar, Consegue absorver apenas com a aula presencial, Não busca outras maneiras de estudar, As vezes, outros $10 \%$ menciona não buscar outras maneiras, o que demonstra uma preocupação aos docentes, pois é nítido que para uma aprendizagem mais eficaz é necessário rever conceitos, tirar dúvidas de algo que foi esquecido ou não foi compreendido, buscar outras formas de pesquisa seria o meio mais eficiente para preencher essa lacuna.

A quarta pergunta, por sua vez, teve o intuito de analisar o ponto de vista dos alunos a respeito das aulas remotas “Você se sente motivado(a) com as aulas não presenciais?”. Os dados estão apresentados no Gráfico 3.

Gráfico 3. Você se sente motivado(a) com as aulas não presenciais?

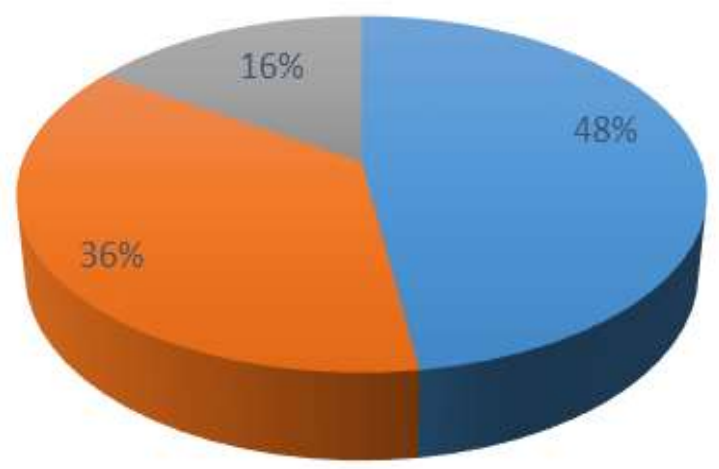

- Sim $\square$ Não As vezes

Fonte: Autores.

Embora as aulas remotas apresentem obstáculos, $48 \%$ dos discentes estão motivados com o ensino remoto. No entanto, é alta a quantidade de alunos sem motivação (36\%) ou que apenas às vezes se sentem motivados (16\%), que se somados formam mais da metade do total de alunos.

Com a intenção de verificar os motivos que induzem esses alunos a apresentarem ou não motivação com as aulas remotas, foi realizada a quinta questão do questionário prévio - “Qual o motivo da sua motivação ou desmotivação?” - em que foi possível analisar as principais razões que levaram os discentes à resposta da quarta questão. A Tabela 3 indica as principais causas que motivam os discentes em aulas não presenciais. 
Tabela 3. Principais motivações para as aulas remotas.

\begin{tabular}{c|c}
\hline Categorias & Respostas dos alunos (\%) \\
\hline Busca de um futuro melhor & 37 \\
Esforço dos professores neste momento & 23 \\
Poder rever as aulas e o conteúdo & 12 \\
Segurança de estar em casa durante a pandemia & 8 \\
Mais conforto e flexibilidade para a realização das atividades & 8 \\
Outros & 12 \\
\hline
\end{tabular}

Fonte: Autores.

Analisando as respostas dos discentes, que responderam se sentir motivados, observa-se que a maior parte (37\%) sente motivação na busca por um futuro melhor. Dentre as respostas é possível destacar: "Motivação que eu quero me formar"; "De cabeça erguida para buscar meu sonho"; "De ser alguém na vida”, sendo assim, é possível analisar que muitos discentes entendem que para atingir o objetivo de ter um futuro promissor é necessário empenho nos estudos, mesmo durante a pandemia, mantendo a dedicação para realização dos seus sonhos e buscar a profissão almejada.

A segunda principal motivação (23\%) é o esforço dos professores neste momento, que também podem ser evidenciado nas respostas dos discentes - "Alguns professores me motivam a estudar pelo fato de dar a aula com tanta dedicação e preocupação em passar o conteúdo para o aluno entender realmente”; “A minha motivação são os professores capacitados que nos traz um ensino de qualidade”; "Eu vejo que os professores estão fazendo de tudo para nos ajudar a conseguir um bom rendimento”. Mediante as dificuldades de alguns docentes como o uso de tecnologias no ensino remoto, fica claro na fala dos discentes, que os mesmos reconhecem a dedicação e a preocupara dos professores neste momento.

O fato de poder rever as aulas e o conteúdo e ter mais conforto e flexibilidade para a realização das atividades é a razão que motiva $12 \%$ e $8 \%$ dos alunos neste período, respectivamente. De fato, a disponibilização de aulas gravadas no ensino proporciona ao discente algumas facilidades, como a autonomia de poder rever a aula, pausar e prosseguir quando necessário. Outro aspecto motivacional é a segurança de estar em casa (8\%) neste período pandêmico.

Os alunos que não se sentiam motivados, ou apenas às vezes, justificaram as suas respostas, alegando os principais motivos da desmotivação com a aula remota (Tabela 4).

Tabela 4. Principais motivos da não motivação para as aulas remotas.

\begin{tabular}{c|c}
\hline Categorias & Respostas dos alunos (\%) \\
\hline Preferência por aulas presenciais & 38 \\
Dificuldade de concentração e foco/desanimo & 24 \\
Conexão com a internet/ficar horas no celular & 12 \\
Conciliar atividades domésticas com estudo/situações familiares & 8 \\
Não ter outra alternativa & 3 \\
Outros & 15 \\
\hline
\end{tabular}

Fonte: Autores.

O principal fator para não motivação dos alunos, é a preferência por aulas presencias (38\%). Analisando as respostas dos discentes, é notável que um percentual significativo não se adaptou a essa nova realidade do ensino - “Acho muito 
importante a presença do professor(a) em sala de aula, a presença do professor em sala de aula é melhor para entender, para tirar dúvidas, para ajudar o aluno quando não está entendendo, etc."; "Nas aulas presenciais consigo entender melhor e prestar mais atenção, nas aulas online eu não me adaptei muito bem, e eu ainda sou bem ruim pra conseguir prestar atenção."; "Minha motivação é que aula presencial você pode tirar dúvida na hora, você participa mais da aula e aprende bem mais."

Outro fator que desmotiva os discentes é a dificuldade de concentração e foco/desanimo, relatos como: "Às vezes não entendo o que estão passando e fico toda vez perdida, não consigo ficar em dias com as tarefas, tenho várias dificuldade e não sei se vou conseguir fechar esse ano, pois realmente eu estou perdida nisso tudo" e "Eu não me sinto bem em ficar muito tempo na frente de um computador e também não consigo me concentrar", evidenciam a dificuldade de concentração dos discentes durante as aulas online.

A conexão com a internet é um problema para parte dos alunos (12\%) que relataram: "Ou eu me esqueço de participar das lives ou minha internet está ruim (moro em fazenda)" e "Porque não é a mesma coisa de estar no presencial, e especialmente eu, venho no vizinho pra pegar internet pra participar das aulas e fazer algumas tarefas porque na minha casa não tem internet e seria muito caro para colocar e do dados móveis não funciona aqui, e como é zona rural a distância entre a minha casa e a do vizinho é grande, além disso a internet cai muito, muito ruim, então tem vez que não me sinto motivado." estes relatos enfatizam problemas recorrentes do Brasil, onde a conectividade é limitada em certas regiões ou as famílias se encontra em situação de vulnerabilidade social. Estas evidencias corroboram com o estudo realizado por Kronbauer (2020) que mostram que as aulas remotas devem ser avaliadas em diversos aspectos, devido as diversas problemáticas presentes em nosso país decorrentes de questões sociais como: pouca infraestrutura na conexão e falta de dispositivos de qualidade para todos os alunos.

Conciliar as atividades domésticas com o ensino remoto não tem sido uma tarefa fácil para alguns estudantes (8\%), como é relatado nas seguintes respostas - "Durante a quarentena aconteceram várias coisas em minha casa, vários problemas familiares, sei que não posso deixar isso afetar, mas é difícil, tanto que estou correndo atrás de fazer todas as atividades pendentes" e "Então em meio à pandemia me mudei duas vezes de casa, vivi em um lar totalmente conturbado e sem estabilidade. Além de vários e vários problemas familiares. Mas nos últimos dois meses tudo melhorou e estou voltando a realizar as atividades não presenciais."

Após analisar as percepções dos discentes com relação ao ensino remoto e diante da intenção de direcionar a pesquisa para o ensino de Química, foi realizado o seguinte questionamento - "Qual a sua maior dificuldade com relação ao ensino de Química?". Conforme mostra na tabela 5, a maioria dos discentes não soube especificar ao certo quais eram suas maiores dificuldades (40\%), esta resposta dificulta o trabalho do professor em analisar os problemas apontados e levar uma alternativa metodológica para sala de aula. No entanto, outra parte dos alunos apontaram suas maiores dificuldades, conforme apresentado na Tabela 5. 
Tabela 5. Qual a sua maior dificuldade com relação ao ensino de Química?

\begin{tabular}{c|c}
\hline Categorias & Respostas dos alunos (\%) \\
\hline Não souberam especificar & 40 \\
Conceitos Químicos & 22 \\
Matemática/cálculos & 15 \\
Formato online & 6 \\
Difícil memorização & 4 \\
Outros & 13 \\
\hline
\end{tabular}

Fonte: Autores.

Observa-se que a matemática é um grande obstáculo para os discentes (15\%) na compreensão da Química. A Química é uma disciplina em que, na maioria de seus conteúdos, necessita da matemática como pré-requisito, a dificuldade em cálculos adquirida ao longo da vida estudantil reflete diretamente no rendimento em Química, como mostra os percentuais.

Deve ser enfatizado que este questionário foi aplicado aos discentes do $1^{\circ}$ Ano do Ensino Médio, em que a ementa de Química trata de assuntos como, modelos atômicos, tabela periódica, configuração eletrônica, entre outros. Todos esses tópicos utilizam de representações como forma de expressar conceitos. Dessa forma, é compreensível que $22 \%$ dos discentes sentem dificuldade na compreensão de certos conceitos químicos, visto que estão aprendendo uma linguagem nova, com diferentes representações simbólicas. Sendo assim, a aplicação de metodologias alternativas de ensino, como os modelos didáticos, são maneiras eficientes de facilitar o aprendizado de conteúdos que exigem capacidade de abstração. Nesse contexto, a pesquisa de Justina \& Feria (2016), confirma que a produção de um material didático para a assimilação de um conteúdo complexo colabora para a contextualização de criticidade dos alunos.

A dificuldade para entender a disciplina é outro impasse evidenciado, como a resposta a seguir: "Eu acho um pouco difícil, por mais que eu me esforço, às vezes não consigo entender”. O formato online trabalhado durante a pandemia tem dificultado o aprendizado de alguns alunos na disciplina de Química, como descrito na seguinte resposta: "A disciplina de Química não é tão fácil, exige muita atenção e estudar Química de forma remota, acho meio complicado entender 100\%, comparado a estar em uma sala de aula. Porém esse é o único meio de aprendizado durante uma pandemia”.

Com intuito de saber a opinião dos discentes a respeito do uso de modelos didáticos em sala de aula, foi realizado o seguinte questionamento - "Você já teve a oportunidade de assistir aulas nas quais se utilizaram modelos didáticos? Conforme apresentado no Gráfico 4, uma porcentagem significativa (71\%) dos discentes não tiveram a oportunidade de participar de aulas que utilizavam modelos didáticos. Além disso, os dados indicam que menos de 30\% dos discentes foram privilegiados ao participarem de aulas com o uso dessa metodologia. Os dados também evidenciam que parte dos profissionais da área da educação não tem a prática de usar modelos didáticos como meio alternativo para o ensino. 
Gráfico 4. Você já teve a oportunidade de assistir aulas nas quais se utilizaram modelos didáticos?

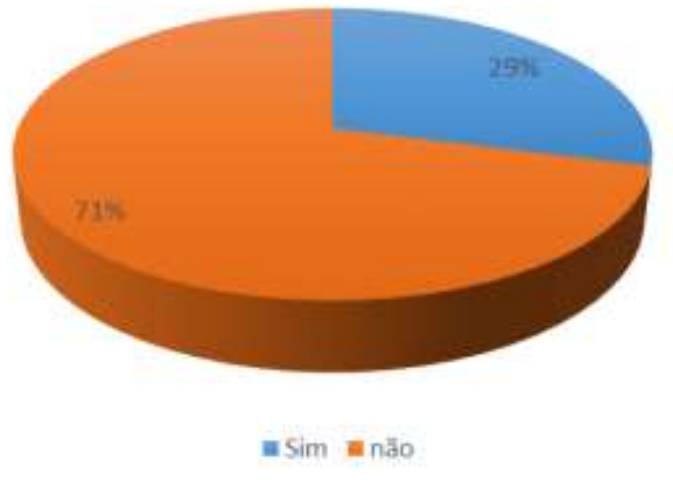

Fonte: Autores.

Diante das respostas do questionário prévio, confirmou-se a necessidade de metodologias de ensino alternativas que auxiliem no processo de aprendizagem dos discentes, principalmente enquanto persistir o ensino remoto.

Após a aplicação do questionário, a segunda etapa da pesquisa consistiu na apresentação dos modelos didáticos (interativo e pedagógico) no formato de vídeo aulas, servindo como material de apoio ao conteúdo teórico visto nas aulas síncronas.

Após a exposição dos modelos, uma terceira etapa da pesquisa compreendeu em enviar um questionário final aos discentes, que teve como finalidade analisar a eficiência da aplicação de modelos didáticos para o ensino de configuração eletrônica.

A primeira pergunta do questionário final - O que você achou da nova forma de ensinar configuração eletrônica através de modelos didáticos? - teve como objetivo validar a aplicabilidade do método, de acordo com o ponto de vista dos discentes.

A alternativa mais assinalada pelos discentes, com 56\% foi "bom", em segundo lugar, 27\% acharam "muito bom". Os dados somados da primeira e segunda resposta totalizam $83 \%$, o que expressam a satisfação dos discentes em ter estudado o conteúdo por meio de modelos didáticos e validando sua eficácia, seja ele interativo ou pedagógico. Este resultado está de acordo com Silva et al. (2016), onde 90\% dos estudantes se sentiram mais motivados com o uso de modelos didáticos. Já 14\% dos alunos avaliaram como razoável e uma parcela ínfima responderam que acharam "ruim ou muito ruim", conforme mostra o Gráfico 5 .

Gráfico 5. O que você achou da nova forma de ensinar configuração eletrônica através de modelos didáticos?

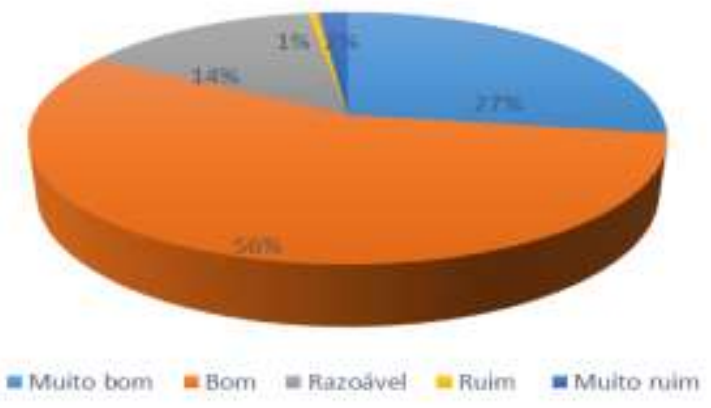

Fonte: Autores. 
O modelo utilizado se mostrou eficaz no auxílio do processo de ensino e aprendizado, certamente, por possibilitar uma dinâmica diferente da convencional, tornando possível que os discentes vislumbrassem conceitos que, muitas vezes, são estudados mecanicamente sem que ocorra uma aprendizagem significativa.

De acordo com a pesquisa realizada por (Rezende \& Gomes, 2018), a realização de aulas com o uso de modelos didáticos, apresentam vantagens por conciliar a teoria à prática, isto garante aos alunos a oportunidade de envolver-se, de maneira dinâmica nas aulas, expondo ideias, elaborando indagações e descobrindo soluções para os problemas propostos.

Pensando nisso, a segunda questão do questionário final - Os modelos didáticos apresentados em vídeo facilitaram a sua compreensão de configuração eletrônica? - teve como propósito verificar a melhoria de aprendizagem com os métodos aplicados.

Analisando as respostas dos discentes, 51\% compreenderam mais facilmente o ensino de configuração eletrônica, 44\% relataram que os modelos didáticos ajudaram um pouco na compreensão do conteúdo e apenas 5\% não compreendeu através da metodologia empregada. Novamente é possível, através dos dados representados no Gráfico 6, asseverar que os modelos didáticos são eficazes, facilitando a absorção do conteúdo.

Gráfico 6. Os modelos didáticos apresentados em vídeo facilitaram a sua compreensão de configuração eletrônica?

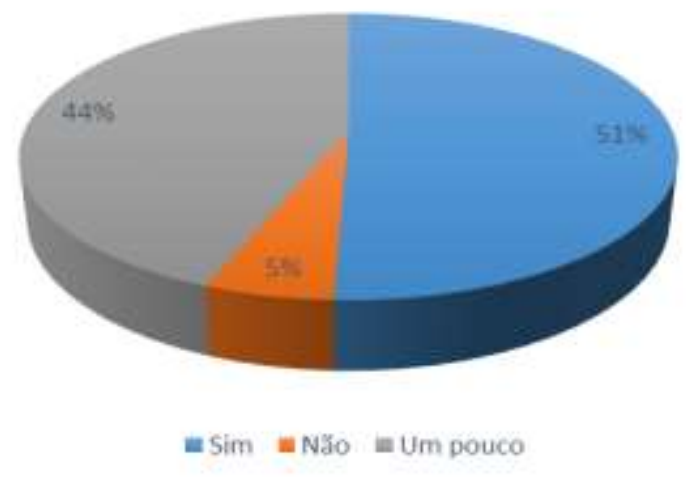

Fonte: Autores.

Analisando as respostas dos discentes ao questionário final, é possível afirmar que de maneira geral, os modelos didáticos desenvolvidos tiveram efeito positivo no que tange à aprendizagem. Com a aplicação dos modelos didáticos desenvolvidos no presente estudo, a compreensão do conteúdo de configuração eletrônica por parte dos discentes apresentou uma melhora significativa.

A terceira questão do questionário final, que diz: "Qual dos modelos apresentados em vídeo foi o mais eficaz para a compreensão de configuração eletrônica?”, foi elaborada a fim de comparar os modelos didáticos (interativo e pedagógico) propostos. Segundo as respostas dos discentes, observou que não houve preferência expressiva por parte deles, uma vez que, 53\% optaram pelo modelo didático interativo e $47 \%$ pelo modelo didático pedagógico (Gráfico 7). Os dados validam mais uma vez que, o uso de modelos didáticos no ensino de Química torna-se bastante eficaz para a compreensão de certos conteúdos, principalmente em tempos de aulas remotas. 
Gráfico 7. Qual dos modelos apresentados em vídeo foi o mais eficaz para a compreensão de configuração eletrônica?

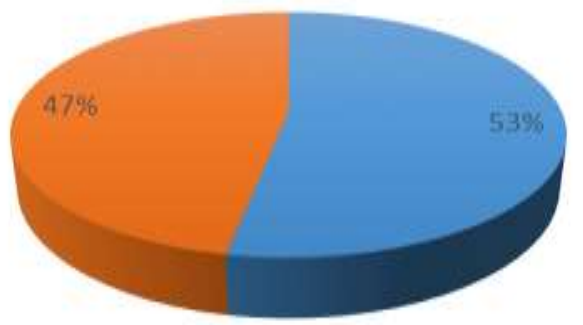

a Modelo didático interativo a Modelo didático pedagógico

Fonte: Autores.

Ao analisar a pesquisa de forma geral, fica evidente que os discentes não estavam preparados para o ensino remoto, em que é necessário se ter organização, autonomia nos estudos e motivação. Além disso, a capacitação dos docentes para o uso de ferramentas digitais e preparação de material audiovisual se faz extremamente necessário. A aprovação desta abordagem foi evidenciada no trabalho de Silva et at. (2014), confirmando que através dos modelos, os discentes mostraram-se mais motivados, tornando a aprendizagem mais significativa. Nesse contexto, as metodologias apresentadas nesse trabalho contribuem significativamente para o ensino de conceitos abstratos na Química, como o conteúdo de configuração eletrônica, em que o discente poderá ampliar a assimilação, tornando um o conteúdo complexo de fácil entendimento.

\section{Conclusão}

A pandemia de Covid-19, doença causada pelo novo coronavírus, extrapola a área da saúde, trazendo impactos na sociedade como um todo. Em 2020, o distanciamento social, embora que correto para evitar a disseminação da doença, afetou as instituições de ensino em todo mundo e, instalou-se uma nova realidade, tanto para os estudantes quanto para os profissionais da área da educação. O ensino remoto foi uma solução encontrada temporariamente para que os discentes não perdessem o vínculo com a escola e dessem segmento aos estudos, porém essa modalidade trouxe à tona uma série de dificuldades.

Uma dessas dificuldades pode estar associada ao ensino de Química, em que os conteúdos, geralmente são abstratos e complexos e, a falta da presença física do professor para explicá-los pode trazer prejuízos ao aprendizado do estudante. Assim, se faz 53\% 47\% Modelo didático interativo Modelo didático pedagógico extremamente necessário o uso de metodologias alternativas para o ensino, como por exemplo o uso de modelos didáticos interativos e pedagógicos.

Diante dessas questões, no presente trabalho pareceu-nos uma boa estratégia associar a situação de aulas remotas com o ensino de Química para aplicação de uma metodologia mais dinâmica e que utilizasse material áudio visual para melhor compressão e motivação dos estudantes.

A análise dos dados coletados no questionário prévio e final mostrou que a utilização de modelos didáticos simples e baratos apresentou ser eficiente para auxiliar na aprendizagem do conteúdo de configuração eletrônica, tendo em vista que, para melhorar o seu desempenho escolar, os discentes indicaram que buscam outras formas de estudar os conteúdos de Química. Como meio alternativo, relataram que procuram outras plataformas de ensino online para auxiliar no processo, o que acaba mostrando a importância e a evolução que as tecnologias nos proporcionam.

A aplicação dos modelos didáticos propostos nesse trabalho como alternativa ao ensino de configuração eletrônica se mostrou satisfatório na visão dos discentes, pois a maioria relatou não ter participado de aulas presenciais ou não presenciais 
que utilizasse esse tipo de metodologia. Ao se fazer a comparação entre o modelo didático interativo e pedagógico, não houve uma preferência significativa por parte dos discentes, mas ficou claro que a necessidade dos docentes em buscar alternativas diferentes das convencionais é relevante para tornar as aulas, sejam elas presenciais ou remotas, de maneira mais interativa, apoiando-se das tecnologias disponíveis. Assim, os modelos didáticos apresentados nesse trabalho, traz uma proposta diferente que pode ser facilmente empregada nas aulas de Química para as turmas de $1^{\circ}$ ano do Ensino Médio, assim como ideia para elaboração em outros conteúdos da Química.

Esses resultados nos motivam a continuar contribuindo para o ensino de Química, pesquisando novas metodologias de ensino que sejam aplicáveis nas aulas remotas, principalmente enquanto durar o período pandêmico.

\section{Referências}

Bianco, A. A. G. \& Meloni, R. A. (2019). O Conhecimento Escolar: Um Estudo do Tema Diagrama de Linus Pauling em Livros Didáticos de Química 1960/1970. Química Nova na Escola, 41(2), 148-155.

Brasil \& MEC (2002). PCN + Ensino Médio: Orientações Educacionais complementares aos Parâmetros Curriculares Nacionais - Ciências da Natureza, Matemática e suas Tecnologias.

Brasil. (2018). Ministério da Educação. Base Nacional Comum Curricular: Educação é a base. Brasília: MEC, 2018. Recuperado de http://basenacionalcomum.mec.gov.br/images/BNCC_EI_EF_110518_versaofinal_site.pdf.

Corrêa, J. N. P. \& Brandemberg, J. C (2021). Tecnologias digitais da informação e comunicação no ensino de matemática em tempos de pandemia: desafios e possibilidades. Boletim Cearense de Educação e História da Matemática, 8(22), 34-54.

Gil, A. C (2016). Como elaborar projetos de pesquisa. (5a ed.), Atlas.

Gonçalves, L. de J., Veit, E. A. \& Silveira, F. L. (2006). Textos, Animações e Vídeos para o ensino-aprendizagem de Física Térmica no Ensino Médio. In: Encontro Estadual de Ensino de Física. (UFRGS), 93-101.

Heckler, V., Saraiva, M. F. O. \& Filho, K. S. O. (2007). Uso de simuladores, imagens e animações como ferramentas auxiliares no ensino/aprendizagem de óptica. Revista Brasileira de Ensino de Física. 29(2), 267-273

Justina, L. A. D. \& Feria, M. R. (2006). A utilização de modelos didáticos no ensino de genética - exemplo de representação de compactação do DNA eucarioto. Arq. Mundi, 10(02), 35-40.

Kronbauer, A. E. (2020). Um desenho metodológico para engajar e motivas os alunos nas aulas remotas na pandemia do Covid-19. Interfaces Científicas, $8(03), 611-626$

Moreira, J. A., Henriques, S. \& Barros, D. (2020). Transitando de um ensino remoto emergencial para uma educação digital em rede, em tempos de pandemia. Dialogia, 34, 351- 364 .

Neto, H. DA S. M. \& Moradillo, E. F. (2016) O Lúdico no Ensino de Química: considerações a partir da psicologia histórico-cultural. Química Nova na Escola, 38(4), 360-368.

Oliveira, A. S. S., Neto, A. B. A. \& Oliveira, L. M. S. (2020). Processo Ensino Aprendizagem na Educação Infantil em tempos de Pandemia e Isolamento. Ciência Contemporânea, 1(6), 349-364.

Rezende, L. \& Struchiner, M. (2009). Uma Proposta Pedagógica para Produção e Utilização de Materiais Audiovisuais no Ensino de Ciências: análise de um vídeo sobre entomologia. Alexandria: Revista de Educação em Ciência e Tecnologia, 2(1), 45-66.

Rezende, L. P. \& Gomes, S. C. S. (2018). Uso de modelos didáticos o ensino de genética: estratégias metodológicas para o apre ndizado. Revista de Educação, Ciências e Matemáticas. 8(2), 45-66.

Sales, P. F. (2020). "Químiemcasa": aspectos de um processo de ensino para a aprendizagem de Química em épocas de pandemia. Research, Society and Development, $9(11), 1-19$.

Sanches, C. E. (2016). PowerPoint como ferramenta educacional e sua contextualização nas TICs. Revista Tecnologias na Educação, $15,1-9$.

Senhoras, E. M. (2020). Coronavírus E Educação: Análise Dos Impactos Assimétricos. Boletim de Conjuntura (BOCA), 2(5), 128-136.

Silva, A. A. da, Filha, R. T. da S. \& Freitas, S. R. S. (2016). Utilização de modelo didático como metodologia complementar ao ensino de anatomia celular. Biota Amazônia, 6(03), 17- 21.

Silva, E. E. da, Ferbonio, J. T. G., Machado, N. G. Senra, R. E. F. \& Campos A. G. de (2014). O uso de Modelos didáticos como Instrumento Pedagógico de Aprendizagem em Citologia. Revista de Ciencias Exatas e Tecnológica, 9(09), 65-75.

Silva, J. N., Amorim, J. S., Monteiro, L. P. \& Freitas, K. H. G. (2017). Experimentos de baixo custo aplicados ao ensino de química: contribuição ao processo ensino-aprendizagem. Scientia Plena, 13(01), 1-11. 
Research, Society and Development, v. 10, n. 4, e22710413978, 2021

(CC BY 4.0) | ISSN 2525-3409 | DOI: http://dx.doi.org/10.33448/rsd-v10i4.13978

Valente, G. S. C., Moraes, E. B de, Sanchez, M. C. O., Souza, D. F. de \& Pacheco, M. C. M. D.(2020). O ensino remoto frente às exigências do contexto de pandemia: Reflexões sobre a prática docente. Research, Society and Development, 9(9). 1-13. 